\title{
Análise morfológica dos crioulos do Golfo da Guiné e do kabuverdianu
}

\author{
Shirley Freitas \\ Universidade de São Paulo (USP), São Paulo, São Paulo, Brasil \\ shirleyfreitas@usp.br \\ Manuele Bandeira \\ Universidade de São Paulo (USP), São Paulo, São Paulo, Brasil \\ manuelebandeira@usp.br
}

DOI: $\underline{\text { http://dx.doi.org/10.21165/el.v45i1.653 }}$

\begin{abstract}
Resumo
Neste artigo, investigaremos os processos morfológicos de itens lexicais nas línguas crioulas de base portuguesa do Golfo da Guiné e no kabuverdianu. Segundo McWhorter (1998), as línguas crioulas são mais simples do que as línguas não crioulas. De forma análoga, Thomason (2001) apresenta a hipótese da transparência semântica, segundo a qual nos casos em que a morfologia aparece em pidgins e crioulos (algo que não é comum), ela tende a ser regular, transparente, sem as irregularidades comumente encontradas em línguas não crioulas. A despeito desses estudos e de outros que descrevem os mecanismos gramaticais dos crioulos como "simples" e "sem complexidades", apresentaremos dados que comprovam o uso variado de recursos morfológicos autóctones das línguas estudadas para a criação de novos itens lexicais.
\end{abstract}

Palavras-chaves: línguas crioulas de base portuguesa do golfo da guiné; kabuverdianu; processos morfológicos; morfologia.

\section{Morphological Analysis of Creoles Spoken in Gulf of Guinea and of Cape Verdean Creole}

\begin{abstract}
This paper investigates morphological processes of lexical items in the Portuguese-based creole languages from Gulf of Guinea and in Cape Verdean Creole. According to McWhorter (1998), creole languages are simpler than non-creole languages. In a similar way, Thomason (2001) presents the Semantic Transparency Hypothesis. According to this hypothesis, in cases that morphology occurs in pidgins and creoles (which would not be usual), it tends to be regular and transparent, and not to contain the irregularities commonly seen in non-creole languages. Despite these studies and others that describe the grammatical mechanisms of creole languages as "simple" and "complexless", the paper shows data that prove the varied use of native morphological resources in the languages under examination for the creation of new lexical items.
\end{abstract}

Keywords: portuguese-based creoles from gulf of guinea; cape verdean creole; morphological processes; morphology. 


\section{Introdução}

O presente estudo investiga os processos morfológicos de itens lexicais nas línguas crioulas de base portuguesa do Golfo da Guiné (santome, lung'ie, angolar e fa d'ambô) e no kabuverdianu. A pesquisa se justifica na medida em que a descrição dos processos morfológicos de formação de palavras nessas línguas permitirá contribuir para a ampliação do entendimento sobre as línguas crioulas em geral. Assim, mostraremos que as línguas analisadas, além de possuírem morfologia, apresentam processos morfológicos autóctones, não se limitando a simplesmente importar os padrões morfológicos de sua língua lexificadora (português).

Dessa maneira, o artigo se organiza da seguinte forma: primeiramente, aspectos gerais das línguas em estudo serão apresentados. $\mathrm{Na}$ segunda seção, discutiremos os principais pontos acerca das teorias que defendem a ausência de marcas morfológicas na estrutura gramatical dos crioulos. Traremos, em contrapartida, a perspectiva de que crioulos possuem uma morfologia diversa através de exemplos e dados a serem analisados neste artigo. Antes que seja feita a análise, na terceira seção, demonstraremos os materiais e métodos utilizados para a elaboração da pesquisa. Em seguida, serão apresentados os principais processos morfológicos encontrados nos crioulos portugueses do Golfo da Guiné e no kabuverdianu, tais como a derivação sufixal, a composição, os ideofones e a reduplicação. Por fim, a quinta seção está reservada para as considerações finais e os possíveis desdobramentos desta pesquisa.

\section{Os crioul os de base portuguesa do Golfo da Guiné e o kabuverdianu}

O santome ou forro (falado na ilha de São Tomé), o lung'ie ou principense (falado na itha do Príncipe), o fa d'ambô (falado na ilha de Ano Bom) e o angolar (falado pelas comunidades angolares de São Tomé) são línguas autóctones da região insular do Golfo da Guiné, na África Ocidental. Tais línguas surgiram a partir do contato entre os povoadores portugueses e os escravos africanos, iniciado no último quarto do século XV. Embora, ao serem comparados entre si, apresentem diferenças significativas, os quatro crioulos tiveram uma origem em comum (HAGEMEIJER, 2009). Autores como Günther (1973), Ferraz (1979) e Hagemeijer (2009), entre outros, afirmam que o contato promovido pelo povoamento de São Tomé no final do século $\mathrm{XV}$ teve como consequência o surgimento de uma língua crioula de base lexical portuguesa, o protocrioulo do Golfo da Guiné (PCGG), que ramificou nas quatro línguas (santome, fa d'ambô, lung'ie e angolar).

O santome ou o forro é a língua, depois do português, que possui mais falantes em São Tomé. Atualmente, do total absoluto de 173.015 habitantes, 62.707 falam a língua (INE, 2013). No que tange a sua gênese, o santome é considerado, dentre os quatro crioulos, a continuação no tempo do PCGG (HAGEMEIJER, 2009). Seu surgimento está intrinsecamente relacionado à formação de uma nova sociedade com reivindicações e poderes socioeconômicos próprios quando, em 1515 e 1517, o rei Dom Manuel declarou livres as escravas dadas aos portugueses, assim como os seus filhos (HLIBOWICKA-WEGLARZ, 2012). Essa comunidade de forros muito provavelmente estava presente na origem e consolidação da nova língua falada na ilha (HAGEMEIJER, 2009). 
A ilha do Príncipe está localizada a cerca de $200 \mathrm{~km}$ da costa oeste africana. Em 2010, acomodava uma população estimada em 7.230 habitantes numa área de $142 \mathrm{~km}^{2}$ (INE, 2013). A itha se encontrava inabitada no momento em que os portugueses chegaram, provavelmente no dia 17 de janeiro de 1472 (HENRIQUES, 2000 apud MAURER, 2009). Embora tenha sido descoberta em 1472, somente por volta de trinta anos depois, a ilha começa a ser colonizada. Com o PCGG já constituído, teria sido levado da ilha de São Tomé para o Príncipe no início do século XVI (HLIBOWICKAWEGLARZ, 2012). Com a separação e o posterior isolamento, provocado pelo deslocamento para a ilha do Príncipe, houve a formação do lung'ie. Por ter sido isolado desde muito cedo, de acordo com Hagemeijer (2009), do ponto de vista do léxico e da fonologia, o lung'ie é o crioulo do Golfo da Guiné que mais apresenta léxico de origem edo e o que mais reteve características fonológicas, exclusivas da área onde as línguas edoídes eram faladas.

Ao lado do santome, o angolar é também uma língua autóctone falada na ilha de São Tomé. Os falantes do angolar vivem nas zonas do litoral de São Tomé, no distrito de Caué, entre Ribeira Afonso até Porto Alegre e, no litoral noroeste, a partir de Neves até Bindá, no distrito de Lembá, e ademais, próximos à cidade de São Tomé, existem pequenos grupos de falantes em São João da Vargem, Pantufo e Praia Melão (CEITA, 1991). Para fins de análise, investigou-se o angolar falado na comunidade de São João dos Angolares, uma pequena vila do distrito de Caué. Estima-se que sua população local seja de 6.887 habitantes (INE, 2013). No que tange à gênese do angolar, há três hipóteses concorrentes (SEIBERT, 2004). A primeira hipótese, de origem popular e difundida dentre a população local, formulada no século XIX, defende que os angolares são descendentes dos sobreviventes de um naufrágio de um navio de escravos oriundo de Angola em meados do século XVI. A segunda hipótese alega que os angolares seriam habitantes autóctones de São Tomé e, por essa razão, já estariam presentes na ilha no momento em que os portugueses ali aportaram. Por fim, a terceira hipótese (hipótese dos quilombolas) advoga que os ascendentes dos angolares eram antigos escravos que fugiram para áreas até então inabitadas, construindo uma nova comunidade, posteriormente ampliada com elementos dos recém-fugidos das roças e das cidades, por volta dos séculos XVI e XVII. Seibert (2004) salienta que diversos documentos históricos sobre escravos fugidos e comunidades de fugitivos em São Tomé evidenciam a hipótese dos quilombolas.

Localizada ao sul de São Tomé, Ano Bom (Annobón em espanhol) é uma pequena ilha de $17,2 \mathrm{~km}^{2}$ que possui um número de falantes estimado em 5.600 , sendo cerca de 5 mil na Ilha de Ano Bom, e 600, na diáspora, incluindo a capital Malabo, em outros lugares da Guiné Equatorial Continental e na Espanha (ARAUJO et al., 2013). Quanto ao seu estatuto político, Ano Bom pertence à República da Guiné Equatorial (CALDEIRA, 2007; ARAUJO et al., 2013). Como São Tomé e Príncipe, Ano Bom estava inabitada até a chegada dos europeus. Do período em que foi descoberta até 1778, a itha foi colônia dos portugueses. De 1778 a 1968, Ano Bom passa a ser de domínio espanhol e, a partir de 1968, passa a pertencer à República da Guiné Equatorial.

Formado a partir do contato principalmente do português e de línguas africanas, o kabuverdianu é falado nas ilhas do arquipélago de Cabo Verde: Santo Antão, São Vicente, Santa Luzia, São Nicolau, Boa Vista, Sal (ilhas de Barlavento); Santiago, Fogo, Maio e Brava (ilhas de Sotavento). Como qualquer outra língua, apresenta 
variações, o que, contudo, não significa línguas diferentes. Essas variações são decorrentes das próprias características da colonização das diversas ilhas (diferentes períodos e agentes colonizadores) e também da distância entre as mesmas (RODRIGUES, 2007; LOPES, 2012). As variedades dialetais do kabuverdianu podem ser reunidas em dois grandes grupos (QUINT, 2000a): (i) ilhas de Barlavento, cuja variedade é de desenvolvimento mais recente; (ii) ilhas de Sotavento, que possuem uma variedade mais antiga. É possível ainda distinguir a variedade falada em Santo Antão, que, para Quint (2000a), é tão diferente no âmbito das evoluções fonéticas e morfológicas que poderia estar em um grupo à parte.

Quanto ao seu estatuto, o kabuverdianu é a língua materna de grande parte da população caboverdiana, sendo o sistema preferido para a comunicação diária informal, sobretudo no registro falado. Por outro lado, a língua oficial do país é o português Cabo Verde inclusive faz parte do grupo dos Países Africanos de Língua Oficial Portuguesa (PALOP) -, usado na escolarização, na mídia, nos documentos oficiais e na esfera político-econômica (QUINT, 2000b; PRATAS, 2002; SILVA, 2008; LOPES, 2012; MIRANDA, 2013). Esse quadro cria uma situação de diglossia, na qual duas línguas convivem em um mesmo espaço, mas não gozam do mesmo status sociopolítico.

\section{Sobre a (não) morfologia dos crioulos}

De acordo com a teoria do Protótipo Crioulo, elaborada por McWhorter (1998), as línguas crioulas são mais simples do que as outras línguas. Segundo o autor, as línguas mais antigas e mais "avançadas" têm morfologia, já que acumulam complexidade com o passar do tempo, ao passo que os crioulos não teriam existido por tempo suficiente para adquirir tais complexidades, não possuindo morfologia. Embora tais afirmações tenham alcançado repercussão no âmbito dos estudos crioulos, é preciso salientar que McWhorter não foi o primeiro a falar sobre a simplicidade dessas línguas e a inexistência de morfologia. Em consonância com esse pensamento, mais de uma década antes, Seuren e Wekker (1986) já defendiam que a morfologia se caracterizava como essencialmente ausente nas línguas crioulas.

Nos últimos anos, há um corpo crescente na literatura sobre a morfologia de pidgin e crioulo, em que essas visões tradicionais são desafiadas (ARENDS, 2001; KOUWENBERG, 2003; PLAG, 2005). A primeira crítica feita ao Protótipo Crioulo (ARENDS, 2001) tange ao próprio conceito de complexidade referida por McWhorther: "Qual gramática é mais complexa, aquela com $n$ regras, cada uma com complexidade $C$, ou aquela com $2 n$ regras, cada uma com complexidade C/2?"1 (ARENDS, 2001, p. 180-181, tradução nossa). Como o próprio McWhorther chama a atenção, questões sobre o nível da complexidade não podem facilmente ser respondidas, principalmente devido ao problema da medição dessa complexidade. Além disso, Arends sinaliza o aspecto estritamente quantitativo da análise de McWhorther:

[...] eles (os critérios) são todos do tipo "mais é mais complexo". Uma gramática é julgada ser mais complexa se ela tem mais fonemas (marcados), mais tons, mais regras sintáticas, mais distinções semânticas e/ou pragmáticas gramaticalmente expressas,

\footnotetext{
1 "Which grammar is more complex, the one with $n$ rules, each of complexity C, or the one with $2 n$ rules, each of complexity C/2?" (ARENDS, 2001, p. 180-181)
} 
mais regras morfofonêmicas, mais casos de analogia, alomorfia, concordância. Aspectos qualitativos de complexidade, tais como complexidade interna das regras em si, não são levados em consideração. ${ }^{2}$ (ARENDS, 2001, p. 180, tradução nossa)

McWhorther (1998) propõe um sistema de medida baseado em quatro critérios principais relacionados à fonologia, à sintaxe, às categorias (morfológicas e sintáticas) e distinções gramaticais e, por fim, à morfologia flexional. Para Arends (2001), os critérios não seriam ilegítimos, no entanto, o que permanece sem razão seria por que a esses quatro critérios é atribuída tal significação, ao invés de quaisquer outros critérios também cogitáveis e plausíveis. Ademais, Arends (2001) alerta que, em inglês, é justamente a ausência de morfologia nas raízes que torna o sistema complexo.

O segundo ponto da crítica ao Protótipo Crioulo diz respeito à caracterização dos crioulos como línguas sem muitas complexidades devido à falta de tempo para se desenvolverem, se comparados às línguas não crioulas. Sobre isso, Pratas (2002) questiona:

Dizer que não houve tempo para os "aperfeiçoamentos" deverá implicar que estamos a referir-nos aos primeiros anos do contacto de línguas, e não aos quatro ou cinco séculos que se lhe seguiram; se assim não for, qual falta de tempo? Mas, acima de tudo, que "aperfeiçoamentos"? Não será precisamente porque uma língua tem em si todos os elementos estruturais necessários aos seus falantes (a quaisquer falantes, e não a uns em particular) que ela não precisa de se "aperfeiçoar"? (PRATAS, 2002, p. 10)

Pratas também chama atenção sobre a questão relacionada à morfologia simples dos crioulos, caracterizado frequentemente como resultado das "mutilações" da morfologia verbal das línguas europeias:

[...] o que dizer quanto à morfologia simples do inglês, que nos verbos regulares apresenta apenas um morfema de passado e, no presente, apresenta apenas um morfema de terceira pessoa do singular não tendo nenhum marcador realizado em todas as outras pessoas? Como explicaremos esta "simplicidade"? Terá sido fruto de "mutilações"? Motivadas por que argumento de ordem cultural? (PRATAS, 2002, p. 10)

Ainda sobre o status da morfologia dos crioulos, Thomason (2001) apresenta a hipótese da transparência semântica, segundo a qual nos casos em que a morfologia aparece em pidgins e crioulos (algo que não é comum), ela tende a ser regular, transparente, sem as irregularidades comumente encontradas em línguas não crioulas. Plag (2001) e Braun e Plag (2003), contudo, defendem que a opacidade pode surgir em línguas que foram resultados do contato, tais como os crioulos. Ao observarem o sranam antigo, os estudiosos encontraram formas semanticamente opacas que já ocorriam com frequência nos primeiros estágios de desenvolvimento do crioulo,

\footnotetext{
2 "[...] they (criteria) are all of the type "more is more complex". A grammar is judged to be more complex if it has more (marked) phonemes, more tones, more syntactic rules, more grammatically expressed semantic and/or pragmatic distinctions, more morphophonemic rules, more cases of suppletion, allomorphy, agreement. Qualitative aspects of complexity, such as the internal complexity of the rules themselves, are not taken into account." (ARENDS, 2001, p. 180)
} 
o que contradiz a hipótese da regularidade e transparência semântica, inerentes aos crioulos segundo Thomason (2001).

Embora seja frequentemente afirmado que as línguas crioulas carecem de morfologia, é possível encontrar outras contra-evidências nos crioulos, como o sufixo transitivo do tok pisin e o prefixo de diminutivo do fa d'ambô (cf. THOMASON, 2001; SEGORBE, 2007). Segundo Segorbe (2007), no fa d'ambô, utiliza-se o prefixo <ná> para formar diminutivos como: ná-mosa 'mocinha' cuja base lexical é mosa 'moça, garota, mulher', ná-mezal ná-bafitu 'mesinha' cujas bases lexicais são mezal bafitu 'mesa'. Assim, tem-se a estrutura geral no fa d'ambô de $(P R E F)$ ná + raíz (nome) = nome no diminutivo. Ademais, tem sido demonstrado que línguas como o papiamentu e o haitiano preservaram (ou reconstruíram) morfemas derivacionais de suas línguas lexificadoras como o-dor e o-mento.

Outro contraexemplo pode ser encontrado no complexo sistema pronominal do kabuverdianu (variante de Santiago) que apresenta formas fortes, formas livres e clíticos (PRATAS, 2013):

\section{Quadro 1. Sistema pronominal do kabuverdianu ${ }^{3}$}

\begin{tabular}{|l|l|l|l|l|}
\hline & Formas fortes & Formas livres & Clíticos de sujeito & Clíticos de objeto \\
\hline $\mathbf{1 s g}^{\mathbf{4}}$ & $A m i$ & $M i$ & $N$ & $-m^{5}$ \\
\hline $\mathbf{2 s g}$ (informal) & $A b o$ & $B o$ & $B u$ & $-b u /-u$ \\
\hline $\mathbf{2 s g}$ (form, masc) & $A n h o$ & $N h o$ & $N h u$ & \\
\hline $\mathbf{2 s g}$ (form, fem) & Anha & $N h a$ & $N h a$ & \\
\hline $\mathbf{3 s g}$ (fem, masc) & $A e l$ & $E l$ & $E$ & $-l$ \\
\hline $\mathbf{1 p l}$ & Anos & Nos & $N u$ & $-n u$ \\
\hline $\mathbf{2 p l}$ & Anhos & Nhos & Nhos & \\
\hline $\mathbf{3 p l}$ & Aes & Es & Es & $-s$ \\
\hline
\end{tabular}

Nesse primeiro quadro, é possível notar que somente as formas de segunda pessoa do singular, em tratamento formal, equivalentes a o senhor e a senhora, apresentam marca de gênero. Nas demais formas, a referência de gênero é conseguida através do contexto discursivo (PRATAS, 2002). As formas livres, presentes no quadro, são formas que podem ser separadas do verbo, no caso das formas fortes são formas que preenchem a posição de tópico e se encontram em contexto de redobro. Isso confirma a afirmação de Plag (2005, p. 7, tradução nossa) de que "[...] em princípio, não há um limite maior para o poder formal do sistema morfológico de pidgins e crioulos do que aquele encontrado em outras línguas."

Embora McWhorther (1998) tenha trazido novamente a noção de complexidade nas línguas para a discussão, sua noção do que é complexo no âmbito linguístico permanece demasiadamente vaga. Além disso, a dificuldade seria para que falante? Como Arends (2001, p. 181-182, tradução nossa) pontua: "Não se diz se a língua será difícil para o aprendiz de L1 ou L2, nem avalia a língua sobre qualquer coisa mais do

\footnotetext{
${ }^{3}$ Quadro retirado de Pratas (2013).

4 Abreviaturas: 1sg: $1^{\mathrm{a}}$ pessoa do singular (etc.); 1pl: $1^{\mathrm{a}}$ pessoa do plural (etc.); form: formal; masc: masculino; fem: feminino.

5 O hífen usado nessa coluna de clíticos de objetos foi usado para marcar o padrão gráfico que convencionalmente indica a escrita de tais clíticos com o hífen.

6 " $[\ldots]$ there is in principle no greater limit to the formal power of the morphological system of pidgins and creoles than to that of other languages." (PLAG, 2005, p. 7)
} 
que um nível intuitivo." De forma análoga, Thomason (1996) argumenta que a classe de línguas em contato não corresponde a qualquer tipologia estrutural:

Essa definição [de línguas de contato] é fundamentalmente histórica; é baseada em diversidade nas fontes de estruturas linguísticas, em vez de características tipológicas da língua. A razão para insistir na definição histórica é que definições sincrônicas não funcionam; não existe, por exemplo, uma lista mestre de traços linguísticos que sejam universalmente compartilhados por, e exclusivamente por, línguas de contato, ou mesmo pidgins e crioulos como um conjunto. ${ }^{8}$ (THOMASON, 1996, p. 3, tradução nossa)

Essa visão é defendida por um corpo crescente na linguística como Plag (2005) que afirma que "[...] embora os pidgins e crioulos pareçam ter menos morfologia do que suas línguas lexificadoras, há de fato uma morfologia em pidgins e crioulos, com diferenças importantes entre línguas individuais e também entre línguas de diferente status (pidgin ou crioulo)." (PLAG, 2005, p. 2, tradução nossa). Tendo em vista a breve discussão acerca da morfologia crioula, compartilhamos com Thomason (2001, p. 169, tradução nossa) a crença de que "[...] os pidgins e crioulos possuem muito mais diversidade estrutural do que os especialistas costumavam visualizar" ${ }^{\prime 0}$. Para ilustrar isso, neste artigo, discutiremos os dados encontrados nos crioulos de base portuguesa falados no Golfo da Guiné e no kabuverdianu.

\section{Materiais e métodos}

O corpus deste trabalho foi formado por itens lexicais em que se verificaram processos de formação de palavras nas variedades modernas do kabuverdianu e dos crioulos de base portuguesa do Golfo da Guiné. As palavras do kabuverdianu foram coletadas no dicionário de Brüser et al. (2002) e em Freitas (em preparação). Já para o Golfo da Guiné, recorremos a Araujo e Hagemeijer (2013), Araujo, G., Agostinho, Araujo, V. e Bandeira (em preparação) e Bandeira (em preparação).

Durante a pesquisa, o trabalho com os dados seguiu algumas etapas. Primeiramente, houve o levantamento de dados, em que, a partir das fontes citadas anteriormente, foram selecionados os vocábulos. Em seguida, os itens lexicais coletados das fontes escritas dos crioulos de base portuguesa do Golfo da Guiné foram gravados com pelo menos dois falantes nativos (para cada palavra). No processo de gravação, as palavras foram lidas pelos falantes, a partir da escrita, de forma isolada. As gravações com falantes nativos foram necessárias em virtude de, algumas vezes, uma determinada

\footnotetext{
7 "It does not tell whether a language will be difficult for an L1 learner or an L2 learner, neither does it evaluate language on anything more than an intuitive level." (ARENDS, 2001, p. 181-182)

8 "This definition [of contact languages] is fundamentally historical; it is based on diversity in the sources of linguistic structures, rather than on (say) typological characteristics of the language. The reason for insisting on a historical definition is that synchronic definitions don't work; there is, for instance, no such thing as a master list of linguistic features that are universally shared by, and exclusive to, contact languages, or even pidgins and creoles as a set." (THOMASON, 1996, p. 3)

9 “....] even though pidgins and creoles seem to have less morphology than their lexifiers, there is indeed morphology in pidgins and creoles, with important differences between individual languages and also between languages of different status (pidgin or creole)." (PLAG, 2005, p. 2)

10 "[...] pidgins and creoles display much more structural diversity than specialists used to envision." (THOMASON, 2001, p. 169)
} 
palavra poder ser escrita de uma forma não prevista nos sistemas gráficos das línguas. Além disso, a partir das conversas com os falantes, foi possível verificar se a palavra era de fato usada ou não. No caso dos dados do kabuverdianu, não foi possível realizar uma viagem de campo, recorrendo-se às transcrições presentes em Brüser et al. (2002) e a conversas com um falante nativo de kabuverdianu que mora em São Paulo. Em seguida, os processos de formação de palavras foram analisados à luz do arcabouço teórico discutido na seção anterior.

\section{Processos de formação de palavras}

A partir da análise de dados, observou-se a formação de palavras novas por meio da junção de uma forma nativizada com parte da morfologia das línguas estudadas (santome - ST; lung'ie - LU; angolar - AN; fa d'ambô - FA; kabuverdianu - KV). A pesquisa se debruçou sobre a formação de novos itens lexicais através dos seguintes processos: (a) adição de sufixos, (b) composição, (c) ideofones e (d) reduplicação. Cada processo será visto e discutido separadamente nas próximas subseções.

\section{Derivação sufixal}

As quatro línguas crioulas de base lexical portuguesa do Golfo da Guiné e o kabuverdianu apresentam, em seu léxico, marcadores derivacionais do português, tais como o -mentu. Inicialmente, pode-se supor que o -mentu não seria afixo propriamente dito nessas línguas, mas emprestados em conjunto com as palavras. Como, por exemplo, lêgulamentu (ST) 'regulamento', poder-se-ia dizer que tal palavra foi emprestada como um todo, por essa razão o -mentu não seria um afixo por si só nas referidas línguas. Entretanto, ao se analisarem vocábulos como ndjutu[mentu] (KV) 'falta de respeito', saka[mentu] (LU) 'vômito', benze[mentu] (ST) 'inauguração', nota-se que o-mentu é, de fato, um afixo formador de palavra.

O sufixo -mentu esteve presente em um número significativo das palavras analisadas, contudo, de acordo com os dados, pode-se classificar a sua presença em dois grupos distintos:

(i) o-mentu que já foi tomado de empréstimo em conjunto com a palavra de L2;

(ii) o -mentu como um sufixo legítimo na língua.

Exemplos do grupo (i) podem ser vistos no quadro $2 \mathrm{em}$ que há palavras como naximentu (LU) 'nascimento', proveniente de nascimento em português, ou pagamento (KV) 'pagamento', proveniente de pagamento em português. Nota-se que mentu, nesses vocábulos do grupo (i), não funciona como sufixo, mas como parte integrante da palavra ${ }^{11}$.

11 Um revisor chamou atenção para o fato de que casos como naximentu e pagamento podem ser analisados como possuindo um sufixo, assim como a palavra do português medicamento, que poderia ser oriunda de duas vertentes: (i) derivação do verbo medicar; (ii) evolução da forma latina medicamentum. Ademais, segundo o revisor, para as línguas crioulas estudadas, é possível conjecturar que a análise do mentu como um sufixo nesses vocábulos é o que permite que os falantes criem novas palavras a partir desse elemento. Brüser et al. (2002), discutindo dados do kabuverdianu, apresentam um posicionamento semelhante ao sugerido pelo revisor. Em casos como o de (a)prizentason 'apresentação', esses autores sugerem uma dupla explicação para o seu surgimento: empréstimos e derivações internas da língua. Diante dessa possibilidade, pretende-se realizar, em uma pesquisa futura, uma análise mais aprofundada acerca desses casos em que a palavra parece já ter vindo formada do português. 
Quadro 2. Exemplos de itens com o -mentu tomado de empréstimo em conjunto com a palavra

\begin{tabular}{|l|l|l|}
\hline ÉTIMO PORTUGUÊE & ITEM EMPRESTADO & GLOSA \\
\hline Abatimento & Batêmentu (AN) & 'desconto' \\
\hline Casamento & Kazamentu (AN) & 'casamento' \\
\hline Polimento & Pulimentu (ST) & 'polimento' \\
\hline Nascimento & Naximentu (LU) & 'nascimento' \\
\hline Pagamento & Pagamentu (LU) & 'pagamento' \\
\hline Sentimento & Sinchimentu (FA) & 'sentimento' \\
\hline
\end{tabular}

O mesmo não se pode afirmar de palavras do grupo (ii), dispostas no quadro 3, em que há palavras como vivêmentu (LU) 'acolhida' que deriva de vivê (LU) + mentu. Nesse item, por exemplo, nota-se que houve o processo de adição do sufixo mentu, uma vez que não ocorre na língua fonte, o português.

Quadro 3. Exemplos de -mentu como um sufixo legítimo

\begin{tabular}{|l|l|}
\hline BASE & BASE + SUFIXO \\
\hline Saka (LU) 'vomitar' & Sakamentu (LU) 'vômito' \\
\hline Vijya (LU) 'vigiar' & Vijyamentu (LU) 'vigia' \\
\hline Vivê (LU) 'viver' & Vivêmentu (LU) 'acolhida' \\
\hline Subì (FA) 'subir' & Subìmentu (FA) 'subida' \\
\hline Sunzu (FA) 'insultar' & Sunzumentu (FA) 'insulto' \\
\hline Ndjutu (KV) 'tratar sem respeito' & Ndjutumentu (KV) 'falta de respeito' \\
\hline Kabali (KV) 'que não presta, inútil' & Kabalindádi (KV) 'maldade, má-criação, malcriadez' \\
\hline
\end{tabular}

O sufixo -dor também foi encontrado nos itens analisados e, de forma semelhante ao -mentu, é possível categorizar o seu registro em dois grupos distintos:

(i) o -dor que já foi tomado de empréstimo em conjunto com a palavra de L2;

(ii) o -dor como um sufixo legítimo na língua.

Exemplos do grupo (i) podem ser vistos em palavras como jugador (KV) 'jogador', proveniente de jogador em português, ou guvernador (KV) 'governador', proveniente de governador em português. Nota-se que -dor, nestes vocábulos do grupo (i), não funciona como sufixo, mas como parte integrante da palavra.

Quadro 4. Exemplos de itens com o -dor tomado de empréstimo em conjunto com a palavra

\begin{tabular}{|l|l|l|}
\hline ÉTIMO PORTUGUÊ & ITEM EMPRESTADO & GLOSA \\
\hline Pescador & Pisikarô (AN) & 'pescador' \\
\hline Comprador & Cumpaadôl (FA) & 'comprador' \\
\hline Gravador & Gavadô (LU) & 'gravador' \\
\hline Pecador & Pekadô (LU) & 'pecador' \\
\hline Fundador & Fundadô (ST) & 'fundador' \\
\hline Carregador & Klagadô (ST) & 'carregador' \\
\hline
\end{tabular}

Ao observar as palavras do grupo (ii) (que só ocorreram em kabuverdianu), disponíveis no quadro 5, como pintador (KV) 'pintor' que deriva de pintar (KV) 'pintar' + -dor, nota-se que houve o processo de adição do sufixo -dor, haja vista que nenhum desses itens ocorre na língua fonte. 
Quadro 5. Exemplos de -dor como um sufixo legítimo

\begin{tabular}{|l|l|}
\hline BASE & BASE + SUFIXO \\
\hline Lora/Rola (KV) 'revolver(-se), enfardar' & Lorador/Rolador (KV) 'tábua de lavar a roupa' \\
\hline Papia (KV) 'falar, dizer' & Papiador (KV) 'falador \\
\hline Pinta (KV) 'pintar' & Pintador (KV) 'pintor/que pinta (bem)' \\
\hline Rusga (KV) 'ir a uma festa sem ser convidado' & $\begin{array}{l}\text { Rusgador (KV) '(aquele) que gosta de se fazer } \\
\text { convidado' }\end{array}$ \\
\hline $\begin{array}{l}\text { Sensia (KV) 'ficar à espera que lhe seja oferecida } \\
\text { uma parte da comida dos outros' }\end{array}$ & $\begin{array}{l}\text { Sensiador (KV) '(aquele) que fica à espera que } \\
\text { lhe seja oferecida uma parte da comida dos outros' }\end{array}$ \\
\hline
\end{tabular}

\section{Composição}

O processo de composição pode ser entendido como a junção de duas ou mais palavras ou radicais, sem que haja modificação dos elementos formadores. Como se pode observar no quadro 6 , os itens justapostos não sofreram alteração, mas, com o processo de composição, assumem um novo sentido. Itens como lixi 'nariz' e tapa 'obstruir' (ST) possuem significados independentes, quando isolados, mas, ao serem justapostos, passam a ter um significado próprio como lixi-tapa (ST) 'constipação nasal'.

Quadro 6. Exemplos de itens formados por composição

\begin{tabular}{|l|l|l|}
\hline ITEM 1 & ITEM 2 & ITEM COMPOSTO \\
\hline Livlu (ST) 'livro' & Nglandji (ST) 'grande' & Livlu-nglandji (ST) 'dicionário' \\
\hline Lixi (ST) 'nariz' & Tapa (ST) 'obstruir, tapar' & Lixi-tapa (ST) 'constipação nasal' \\
\hline Livu (LU) 'livro' & Dêsu (LU) 'Deus' & Livu-dêsu (LU) 'bíblia' \\
\hline Guárda (KV) 'guardar' & Kumida (KV) 'comida' & Guárda-kumida (KV) 'despensa' \\
\hline Guárda (KV) 'guardar' & Kabésa (KV) 'cabeça’ & $\begin{array}{l}\text { Guárda-kabésa (KV) 'festa sincrética, } \\
\text { pagã-cristã, celebrada pelos pais, padrinhos e } \\
\text { amigos, normalmente sete dias depois do } \\
\text { nascimento da criança' }\end{array}$ \\
\hline
\end{tabular}

\section{Ideofones}

O uso de ideofones também foi encontrado no santome, no lung'ie e no angolar. Esse processo bastante heterogêneo é definido por Doke (1935, p. 118-9 apud ARAUJO, 2009, p. 24) como "uma representação vívida de uma ideia através do som. Uma palavra, comumente onomatopaica, que descreve um predicado, um qualificativo ou um advérbio em relação ao seu modo, cor, som, cheiro, ação, estado ou sua intensidade. [...]". Analisando os ideofones que ocorrem em santome, Araujo (2009) afirma que estes elementos são formas presas, ligadas a vocábulos verbais ou nominais específicos (cada ideofone geralmente se liga a uma única palavra da língua). Tratandose de combinações cristalizadas, devem ser aprendidas pelos falantes, não sendo possível derivar sua formação por meio de regras. Além disso, o ideofone e o vocábulo que ele modifica formam um composto, não podendo ocorrer elementos intervenientes. Quanto à origem dos ideofones, Araujo (2009) considera que essa não é uma questão simples, não se devendo atribuir esses elementos somente à influência do substrato, já que eles também podem ser oriundos de palavras da própria língua e mesmo ter entrado por diversas vias, como adaptação fonológica, reanálise de sintagmas complexos, empréstimos ou code-switching. 
Dentre os dados analisados neste artigo, foram encontrados alguns exemplos de ideofones, como se observa em (01):

$\begin{array}{ll}\text { Baanku (LU) 'branco' } & \text { Baanku fenene (LU) 'branquíssimo' } \\ \text { Mon (ST) 'mão' } & \text { Mon kluklu (ST) 'braço amputado' } \\ \text { Bôbô (AN) 'amarelo' } & \text { Bôbô la-la-la (AN) 'amarelíssimo' } \\ \text { Vêmê (LU) 'vermelho' } & \text { Vêmê bababa (LU) 'vermelhíssimo' } \\ \text { Fyô (LU) 'frio' } & \text { Fyô kôkôk ôo (LU) 'muito frio' } \\ \text { Limpu (ST) 'limpo' } & \text { Limpu pyenepyene (ST) 'limpíssimo' } \\ \text { Yêrê (AN) 'brilhar' } & \text { Yêrê ta-ta-ta (AN) 'brilhar muito' }\end{array}$

Tomando como base as características silábicas dos ideofones apresentadas por Araujo (2009), observa-se que, em todos os exemplos em (01), os ideofones são iniciados por uma consoante, ocorrendo as seguintes estruturas silábicas: CV, CCV, CGV. Além disso, os ideofones estão sujeitos a regras de harmonia vocálica, ocorrendo a repetição de uma mesma vogal. Quanto à forma dos ideofones, predominam casos em que todas as sîlabas (duas ou três) são iguais, havendo um exemplo em que o ideofone tem duas silabas finais idênticas (fenene). Por fim, no que diz respeito à função, em grande parte dos exemplos coletados, os ideofones foram usados para intensificar o vocábulo ao qual estão relacionados. Em síntese, ainda que, em alguns casos, os falantes possam fazer uso de advérbios para realizar a intensificação, o uso de ideofones se mostrou recorrente e característico das línguas crioulas de base portuguesa do Golfo da Guiné, não tendo sido encontrados em kabuverdianu.

\section{Reduplicação}

A reduplicação é um processo morfofonológico que consiste em repetir parte ou o todo de uma palavra, com o intuito de criar distinção lexical (KAGER, 1999). Essa repetição de elementos de uma palavra pode ser parcial (apenas parte da palavra é reduplicada) ou total (a palavra inteira é reduplicada) com o objetivo de criação morfológica. É importante distinguir os casos de reduplicação verdadeira, na qual a parte reduplicada apresenta um conteúdo lexical independente, constituindo uma palavra da língua (por exemplo, em português brasileiro, existem as palavras pega e pega-pega) da chamada pseudorreduplicação, na qual os elementos reduplicados só existem na forma reduplicada. Somente os casos que se encaixam no primeiro grupo interessam para esta pesquisa.

Tomando como base a análise feita para o papiamentu (BANDEIRA; FREITAS, 2012), observamos que a reduplicação também é um mecanismo recorrente nas línguas de base portuguesa do Golfo da Guiné e no kabuverdianu, aplicando-se tanto às categorias gramaticais quanto às categorias lexicais. No nível gramatical, há duas funções desse processo: 
Quadro 7. Exemplos das funções gramaticais da reduplicação nas línguas analisadas

\begin{tabular}{|l|l|l|}
\hline & Item lexical & Forma reduplicada \\
\hline $\begin{array}{l}\text { Intensificação } \\
\text { (input: palavras de qualquer } \\
\text { categoria lexical) }\end{array}$ & Vede (ST) 'verdadeiro' & $\begin{array}{l}\text { Vede-vede (ST) } \\
\text { verdadeiro' }\end{array}$ \\
\cline { 2 - 3 } & $\begin{array}{l}\text { Dôdô (ST) 'doido, maluco, } \\
\text { lunático' }\end{array}$ & $\begin{array}{l}\text { Dôdô-dôdô } \\
\text { 'amalucadamente, } \\
\text { desnorteadamente' }\end{array}$ \\
\hline $\begin{array}{l}\text { Distributiva } \\
\text { (nomes e palavras que se } \\
\text { referem à quantidade) }\end{array}$ & Ũa (ST) 'um' & Ûa-ũa (ST) 'alguns' \\
\cline { 2 - 3 } & Dexi (LU) 'dez' & $\begin{array}{l}\text { Dexi-dexi (LU) 'cem' } \\
\text { Páka-páka (KV) 'em maços, } \\
\text { aos bocados' }\end{array}$ \\
\hline
\end{tabular}

Por outro lado, o nível lexical constitui-se por formas que podem ser relacionadas a uma base, no entanto, desenvolveram um significado especializado. As relações semânticas que se estabelecem podem ser principalmente de dois tipos:

Quadro 8. Exemplos das funções lexicais da reduplicação nas línguas analisadas

\begin{tabular}{|l|l|l|}
\hline & Item lexical & Forma reduplicada \\
\hline $\begin{array}{l}\text { Múltipla ocorrência daquilo que é } \\
\text { veiculado pela palavra-base }\end{array}$ & Xinza (FA) 'cinza' & Xinza-xinza (FA) 'em cinzas' \\
\hline $\begin{array}{l}\text { Objeto ou atividade que tem o que é } \\
\text { descrito pela palavra-base como } \\
\text { característica mais proeminente }\end{array}$ & Yeta (ST) 'esconder-se' & Yeta-yeta (ST) 'esconderijo' \\
\hline
\end{tabular}

Além desses exemplos, há ainda outros com diversas funções, a exemplo da distributiva como em txo-txo-txo 'aos pedaços', mudança de classe gramatical como em sata-sata 'espevitado' e intensificação como em lentu-lentu 'muito lento'.

Quadro 8. Exemplos de reduplicação nas línguas analisadas

\begin{tabular}{|l|l|}
\hline Palavra-base & Forma reduplicada \\
\hline Futi (KV) 'perder a razão, ficar louco' & Futi-futi (KV) 'debater-se, agitar-se, esforçar-se' \\
\hline Pinho (AN) 'espinho' & Pinho-pinho (AN) 'espinhento' \\
\hline Sata (ST) 'pular' & Sata-sata (ST) 'espevitado' \\
\hline Zuntá (FA) 'juntar' & Zuntá-zuntá (FA) 'entremesclar' \\
\hline Lentu (LU) 'lento' & Lentu-lentu (LU) 'muito lento' \\
\hline Djáki (KV) 'bezerro, novilho' & Djáki-djáki (KV) 'carrapateira, mamoneira, rícino' \\
\hline Bóka (KV) 'boca, bico' & Bóka-bóka (KV) 'a sós, em segredo' \\
\hline Fuska (KV) 'ficar bêbado' & $\begin{array}{l}\text { Fuska-fuska (KV) 'lusco-fusco, noitinha, crepúsculo, } \\
\text { alvorada' }\end{array}$ \\
\hline Txo (AN) 'pouco, pequeno' & Txo-txo-txo (AN) 'aos pedaços' \\
\hline
\end{tabular}

Analisando somente os casos de reduplicação verdadeira, ainda que não tenha sido possível depreender uma função mais expressiva - como no caso do papiamentu conforme Bandeira e Freitas (2012) -, observou-se que as línguas estudadas fazem uso recorrente do mecanismo de reduplicação para criar novas palavras, cujo significado se relaciona de alguma forma com aquele veiculado pela palavra-base.

\section{Consi derações finais}

Segundo a teoria do Protótipo Crioulo (MCWHORTER, 1998), as línguas crioulas seriam mais simples do que as línguas não crioulas. Conforme tal teoria, as línguas mais antigas, não crioulas, apresentam morfologia, pois teriam mais tempo para 
desenvolver complexidades, ao passo que os crioulos não teriam existido por tempo suficiente para adquirir estruturas complexas, não possuindo, por essa razão, morfologia.

A partir da análise de dados, na presente pesquisa, foi observada a criação de palavras por meio da união de uma forma nativizada com parte da morfologia das línguas crioulas de base portuguesa do Golfo da Guiné e do kabuverdianu. Assim, discutiu-se a formação de novos itens lexicais através dos seguintes processos: (a) adição de sufixos, (b) composição, (c) uso de ideofones, e, por fim, (d) reduplicação.

Desse modo, a despeito de estudos que descrevem os mecanismos gramaticais das línguas crioulas como "simples, sem nexo" (SEUREN; WEKKER, 1986, MCWHORTHER, 1998, entre outros), discutimos dados que comprovam o uso variado de recursos morfológicos das línguas crioulas de base portuguesa do Golfo da Guiné e do kabuverdianu para a criação de novos itens lexicais. Assim, contrapomo-nos à ideia de que os crioulos não possuem morfologia.

De todo modo, o presente estudo requer a ampliação das análises acerca dos processos morfológicos das línguas aqui discutidas e novos testes deverão ser feitos para averiguar a existência de mais processos ainda não observados, assim como o comportamento dos compostos sintáticos nas referidas línguas.

\section{REFERÊNCIAS}

ARAUJO, G. Ideofones na língua sãotomense. Papia, Brasilia, v.19, p. 23-37, 2009.

ARAUJO, G.; HAGEMEIJER, T. Dicionário Santome-Português/Português-Santome. São Paulo: Hera, 2013. 172 p.

ARAUJO, G. et al. Fa d'ambô: língua crioula de base portuguesa de Ano Bom. Cadernos de Estudos Linguísticos (UNICAMP), Campinas, v.55, p. 25-44, 2013.

ARAUJO, G.; AGOSTINHO, A.; ARAUJO, V.; BANDEIRA, M. Dicionário Lung'IePortuguês/Português-Lung'Ie. Em preparação.

ARENDS, J. Simple grammars, complex languages. Linguistic Tipology, v.5, p. 180$182,2001$.

BANDEIRA, M. Reconstrução fonológica e lexical do protocrioulo do Golfo da Guiné. Em preparação.

BANDEIRA, M.; FREITAS, S. A reduplicação no papiamentu. Papia, Brasilia, v.22, n.2, p. 323-334, 2012.

BRAUN, M.; PLAG, I. How transparent is creole morphology? A study of early Sranam word-formation In: BOOIJ, G.; VAN MARLE, J. (eds). Yearbook of Morphology 2002, special section on The Morphology of Creole Languages, ed. by Ingo Plag. Dordrecht: Kluwer, 2003. p. 81-104.

BRÜSER, M. et al. Dicionário do Crioulo de Santiago (Cabo Verde) com equivalências de tradução em alemão e português, elaborado por Martina Brüser e André dos Reis Santos (Cabo Verde), com a contribuição de Ekkehard Dengler e Andreas Blum, sob a direcção de Jürgen Lang. Tübingen: Narr, 2002. 889 p. 
CALDEIRA, A. Crenças religiosas e ritos mágicos na ilha de Ano Bom: uma aproximação histórica. Povos e Culturas, v.11, p. 87-111, 2007.

CEITA, M. N. Ensaio para uma Reconstrução Histórico-Antropológica dos angolares de S. Tomé. 1991. Trabalho de Conclusão de Curso. Lisboa: CEA/KCTE. p. 1.

FERRAZ, L. I. The creole of São Tomé. Johannesburg: Witwatersrand University Press, 1979. $122 \mathrm{p}$.

FREITAS, S. A contribuição do kabuverdianu e dos judeus sefarditas na formação do papiamentu. Em preparação.

GÜNTHER, W. Das Portugiesische Kreolisch der ilha do Príncipe. Marburg an der Lahn, 1973. $277 \mathrm{p}$.

HAGEMEIJER, T. As línguas de S. Tomé e Príncipe. RCBLPE, v.1, p. 1-29, 2009.

HLIBOWICKA-WEGLARZ, B. A origem dos crioulos de base lexical portuguesa no Golfo da Guiné. Romanica Cracoviensia, v.11, p. 177-185, 2012.

INE. Recenseamento Geral da População e da Habitação: Características Educacionais da População. São Tomé: INE, 2013.

KAGER, R. Optimality Theory. Cambridge: Cambridge University Press, 1999. 152 p.

KOUWENBERG, S. Twice as Meaningful: Reduplication in Pidgin, Creoles and Other Contact Languages. London: Battlebridge Publications, 2003. p. 7-18.

LOPES, F. J. Para uma análise sintática das construções relativas no crioulo da ilha de São Nicolau - Cabo Verde. 2012. 157 f. Dissertação (Mestrado em Filologia e Língua Portuguesa) - Faculdade de Filosofia, Letras e Ciências Humanas, Universidade de São Paulo, São Paulo.

MAURER, P. Principense. Grammar, texts, and vocabulary of the Afro-Portuguese creole of the Island of Príncipe, Gulf of Guinea. London: Battlebridge Publications, 2009. $280 \mathrm{p}$.

MCWHORTER, J. Identifying the Creole Prototype: Vindicating a Typological Class. Language, v.74, n.4, p. 788-818, 1998.

MIRANDA, W. O sintagma nominal do caboverdiano: uma investigação semântica. 2013. 130 f. Dissertação (Mestrado em Linguística) - Faculdade de Filosofia, Letras e Ciências Humanas, Universidade de São Paulo, São Paulo.

PLAG, I. The nature of derivational morphology in creoles and non-creoles. Journal of Pidgin and Creole Languages, v.16, n.1, p. 153-160, 2001.

Morfology in pidgins and creoles. In: BROWN, K. (ed.). Encyclopedia of Language and Linguistics, 2. ed., v.8. Oxford: Elsevier, 2005. p. 304-308.

PRATAS, F. O Sistema Pronominal do Caboverdiano (variante de Santiago). 2002. 136 f. Dissertação (Mestrado em Linguística) - Faculdade de Ciências Sociais e Humanas, Universidade Nova de Lisboa, Lisboa.

PRATAS, F. O sistema pronominal do Caboverdiano. Handout, 2013.

QUINT, N. Grammaire de la Langue Cap-Verdienne. Paris: L'Harmattan, 2000a. 436 p. 
Le CapVerdien: Origines et Devenir d'une Langue Métisse. Paris:

L'Harmattan, 2000b. 353 p.

RODRIGUES, U. Fonologia do caboverdiano: das variedades insulares à unidade nacional. 2007. 443 f. Tese (Doutorado em Linguística) - Instituto de Letras, Universidade de Brasilia, Brasilia.

SEGORBE, A. Gramática descriptiva del fa d'ambô. Barcelona: CEIBA Ediciones, 2007. $587 \mathrm{p}$.

SEIBERT, G. Os angolares da Ilha de São Tomé: Náufragos, Autóctones ou Quilombolas? Textos de História-Dossiê História Atlântica - Revista do Programa de Pós-graduação em História, v.12, n.1/2, p. 44, 2004.

SEUREN, P.; WEKKER, H. Semantic Transparency as a Factor in Creole Genesis. In: MUYSKEN, P.; SMITH, N. (orgs.). Substrata Versus Universals in Creole Genesis. Amsterdam: Benjamins, 1986. p. 57-70.

SILVA, M. D. da. Há artigos no Crioulo de Cabo Verde, variedade de Santiago? 2008. 167 f. Dissertação (Mestrado em Filologia e Língua Portuguesa) - Faculdade de Filosofia, Letras e Ciências Humanas, Universidade de São Paulo, São Paulo.

THOMASON, S. Contact languages: a wider perspective. John Benjamins Publishing, Amsterdam, 1996. 506 p. Language Contact. Edinburgh: Edinburgh University Press, 2001. 310 p.

Recebido em: 21/09/2015

Aprovado em: 02/02/2016 